\title{
Users' Perception towards Energy Efficient Buildings
}

\author{
Nadzirah Zainordin ${ }^{1}$, Siti Marina Abdullah ${ }^{2}$, Zarita Ahmad@Baharum ${ }^{3}$ \\ ${ }^{1}$ Faculty of Build Environment, IMPERIA Institute of Technology, Kelana Jaya, Selangor. \\ ${ }^{2}$ Cheston International (J) Sdn Bhd, 43 Jalan Kuning Dua, Taman Pelangi,84000 Johor Bahru, Johor. \\ ${ }^{3}$ Faculty of Architecture Planning \& Surveying, Universiti Teknologi MARA, 40450 Shah Alam, Selangor. \\ nadzirah@imperia.edu.my, zarit928@salam.uitm.edu.my
}

\begin{abstract}
A well-designed energy efficient building maintains the best environment for human habitation while minimising the cost of energy. The energy efficient buildings are to improve the comfort levels of the occupants and reduce energy use (electricity, natural gas, etc) for heating, cooling and lighting (Development and Land Use Policy Manual for Australia, 2000 and United Nations, 1991). This paperisan inquiry to investigate the users 'perceptions towards lights and space of energy efficient buildings. The researchis based on qualitative and quantitative data collection. The findings revealed that users have mixed feeling towards light and space especially with the use of new working practices i.e. hot desking, hotelling etc.
\end{abstract}

Keywords light, space, user perception, energy efficient building.

eISSN 2514-751X @ C 2018. The Authors. Published for AMER ABRA cE-Bs by e-International Publishing House, Ltd., UK. This is an open-access article under the CC BY-NC-ND license (http://creativecommons.org/licenses/bync-nd/4.0/). Peer-review under responsibility of AMER (Association of Malaysian Environment-Behaviour Researchers), ABRA (Association of Behavioural Researchers on Asians) and cE-Bs (Centre for EnvironmentBehaviour Studies), Faculty of Architecture, Planning \& Surveying, Universiti Teknologi MARA, Malaysia.

DOI: https://doi.org/10.21834/aje-bs.v3i6.250 


\subsection{Introduction}

Energy efficient building design is not just the result of applying one or more isolated technologies (C C Wah, 2010). Wah (2010) suggested that it is an integrated whole-building process that requires advocacy and action on the part of the design team throughout the entire project development process. The whole-building approach is easily worth the time and effort, as it can save $30 \%$ or more in energy costs over a conventional building designed. Moreover, energy efficient design does not necessarily have to result in increased construction costs. Indeed, one of the key approaches to energy efficient design is to invest in the building's form and enclosure(e.g., windows, walls) so that the heating, cooling, and lighting loads are reduced, and in turn, smaller, less costly heating, ventilating, and air conditioning systems are needed.

Well-designed energy efficient buildings maintain the best environment for human habitation while minimising the cost of energy. The energy efficient buildings are to improve the comfort levels of the occupants and reduce energy use (electricity, natural gas, etc) for heating, cooling and lighting (Development and Land Use Policy Manual for Australia, 2000 and United Nations, 1991). Janssen (2004) claims that an improvement in energy efficiency is considered as any action undertaken by a producer or user of energy products, that decreases energy use per unit of output, without affecting the level of service provided.

\subsection{Background of Study}

The energy consumed in Malaysia is $90 \%$ in the form of electricity. If these trends continue, buildings will consume almost as much as industry and transport combined. This is quite alarming as Malaysia has one of the fastest growing building industry in the world (ABCSE, 2005). Although this may be a cause for concern, but it does provide opportunities for the development of sustainable energy technology.

The major energy users in Malaysian office building is air conditioners $(57 \%)$, followed by lighting (19\%), lifts and pumps (18\%) and other equipment (6\%) (R. Saidur, 2009). The increased of living standard, had resulted in the increase of electricity used particularly in hot and humid periods which caused by the growing demand for air conditioners to provide thermal comfort for the occupants (Wong and Li, 2007).

The energy consumption in buildings is in terms of the Building Energy Index (BEI). The South East Average BEl is $233 \mathrm{kWh} / \mathrm{m}^{2} / \mathrm{yr}$ - the Malaysian and Singaporean average are $269 \mathrm{kWh} / \mathrm{m}^{2} / \mathrm{yr}$ and $230 \mathrm{kWh} / \mathrm{m}^{2} / \mathrm{yr}$ respectively.

In 1989, the Malaysian Ministry of Energy, Water and Communication (MEWC) had introduced the Guidelines for Energy Efficiency in Non- Domestic Buildings. The guidelines were renamed and revised as the Malaysian Standard MS 1525:2007. The fundamental aim of this Standard is to encourage the application of renewable energy in new and existing buildings to minimise non-renewable energy sources, pollution and energy consumption whist maintaining comfort, health and safety of the occupants. However, this Standard does not ensure that all new buildings will be built as low energy buildings. It will be difficult for the Malaysian government to immediately set standards as mandatory. Nevertheless, it might improve the current situation slightly above the average of construction industry practice. 
The reviewing, updating and improving of the Standard need to be done constantly in order to ensure that energy efficiency in buildings in Malaysia will continuously improve.

\subsection{Problem Statement}

Energy efficiency office building can influence the satisfaction of the user. A study by the New Building Institute (2008) found that $30 \%$ of LEED- rated buildings (Leadership in Energy and Environmental Design) perform better than expected, 25\% perform worse than expected, and a handful of LEED buildings have serious energy consumption problems. These problems may be caused by technical failures, too high expectations, or by inappropriate operation and use. Thus, this study is aimed to investigate the user perception towards light and space of energy efficient buildings in Malaysia.

\subsection{Methodology}

This paper is based on a case study of an energy efficient building owned by the Ministry of Energy, Green Technology and Water also known as KETTHA building. Respondents were the user of the buildings. Structured questionnaire were sent to 200 respondents.

KETTHA building is constructed with the design supported from the Danish Agency for Development Assistance (DANIDA formerly known as DANCED). It is supposed to be a showcase building for energy efficiency and low environmental impact. The objectives of KETTHA building are:

1. To showcase an energy efficient and intelligent building without compromising users' comfort.

2. To show the commitment of the Government through "Leadership by Example".

3. To enhance awareness on energy efficiency building design (integrated approach in building design).

4. To increase local capacity in energy efficiency design building design.

5. To demonstrate the feasibility of energy efficiency design standards as in MS1525:2001 Code of Practice on the use of RE \& EE in Non- Residential Buildings.

Energy efficiency features of KETTHA building are as follow (www. kettha.gov.my):

\subsection{Passive Element}

\subsubsection{Building orientation}

In the KETTHA Building, the windows are primarily orientated to the North and the South. This orientation receives less direction sunshine, and only shallow out shading is required to shade off the sun. East and west orientation receives more sun, and the sun is more difficult to shade difficult to shade off due to the low sun angles for the radiation in the morning and in the afternoon. Exterior shading is most efficient, as the sun is stop before it entering the building. In the KETTHA Building, two type of window façade are used: The punch hole window facades in the lower floors, and curtain wall windows with exterior shading louvers 
in the upper floors. Towards the east, shading is deeper to protect against the low morning sun. The windows constitute $25-39 \%$ of the façade area, depending on orientation. The western façade has virtually no windows.

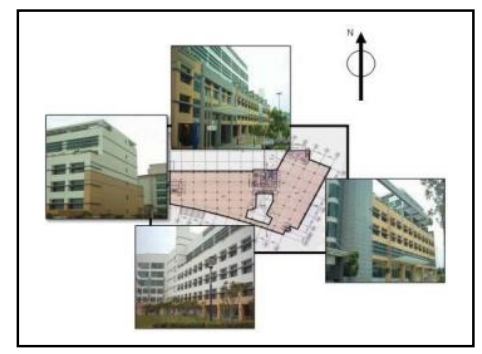

Picture 1.1: Building Orientation

Source: KETTHA Building

The window glazing is a $12 \mathrm{~mm}$ thick light green tinted glazing. The walls of the KETTHA building consists of $200 \mathrm{~mm}$ aerated concrete and exterior surface have light colours to reduce solar heating of the walls. The lightweight concrete walls have an insulation value 2.5 times better than that of a traditional brick wall. The roof of the building is insulated with $100 \mathrm{~mm}$ of insulation, compared to normally only $25 \mathrm{~mm}$ of insulation. Furthermore, the roof surface is protected by a second canopy roof, which prevents direct solar radiation onto the roof. Along the perimeter of the roof, green landscaping provides shading and improves the aesthetics of the roof areas, which can be used for various functions.

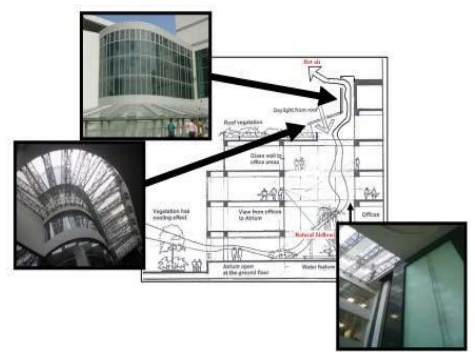

Picture 1.2: The Atrium in Building Sources: KETTHA building Interior Space Layout Design

The physical orientation of a building is a significant impact on its energy consumption. If most of the facade - and, therefore, windows - face east, they will trap the morning sun; while those facing west will let in the afternoon heat. It is moreover hard to shade windows that face either east or west because the sun sits low in the horizon both in the morning and late afternoon. In tropical countries, therefore to reduce the direct absorption of heat from 
the sun, it is best for the main facades of a building to face the north and south. This simple yet pragmatic policy is been adopted in the KETTHA building. In the KETTHA building, permanent working areas are concentrated along the perimeter were there is maximum daylight. Secondary functions, such as storerooms and smaller meeting rooms, meanwhile, are relegated to the interior, where there is only artificial lighting. As far as possible, an open design concept has been adopted as this encourages greater interaction between staff and creates an enhanced feeling of well-being.

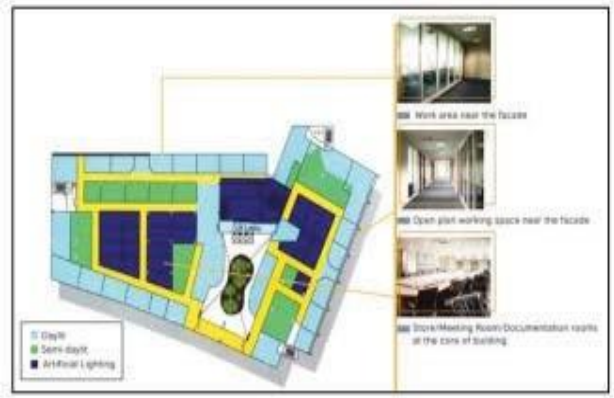

Picture 1.3: Layout Interior Building Source: KETTHA building

\subsubsection{Day lighting}

Natural light is the preferred light source for the human beings. This perception has now also been scientifically proven: People prefer daylight, be in the offices or in shop, as our children learn more and better in Day lit School. Furthermore, daylight is a free source, which is available throughout the normal office hour. The challenge in daylight design of buildings is to design windows and shading which lets daylight in, prevent sunlight to enter the building, and reduces glare problems from the windows. In the KETTHA building, these criteria are achieved through a combination of exterior shading and a glazing, which allows $65 \%$ of the light through, and allows only $51 \%$ of the heat trough. The atrium allows daylight access to deeper parts of the building, thereby improving energy savings and user comfort. In order to fully utilised daylight to offset artificial lighting, the artificial has to be controlled so that it is automatically shut off when daylight is sufficient to satisfy the lighting need, which is an illumination level 300-400 Ix. In the KETTHA building, daylight responsive control system on lighting system is combined with a motion detector, which automatically shuts off lighting and reduce cooling once an office is unoccupied. In the future, advances glazing will become available. Glazing that filters the sunlight such that visible light has preference and the solar heat is avoided. These spectrally selective glazing reflect the invisible infrared and ultraviolet and heat away from the building. Such spectrally reflected glazing, which normally will be combined with sealed double windows will significantly improve energy efficiency of buildings, and more architectural freedom with respect to façade design will be possible. 


\subsubsection{Windows Shading}

The windows of the KETTHA building are "protected" by appropriate shading mechanisms to allow for maximum light to penetrate while minimizing the transfer of heat. Two types of window facades have been used - punch hole facades in the lower floors and curtain wall with exterior louvers in the upper floors. Punch hole windows have double shading mechanisms - the overhang and the lightshelf. These act to prevent the direct penetration of sunlight. Instead, the sun's rays hit the top of the light shelf from where it is reflected into the room. This diffusing action takes away much of the heat, while allowing sufficient light to enter. Diffused natural light carries half the amount of heat as traditional fluorescent lighting for the same level of luminosity. Measuring the efficiency of light sources in terms of luminosity (lumen) against unwanted heat(watts), diffused daylight produces 120 lumen/watt, as compared to the 60 lumen/watt of fluorescent lighting. Few windows in the building that do face east are more heavily shaded to protect against the low morning sun. Added protection against heat is afforded by $12 \mathrm{~mm}$-thick light green noted glazing on the panes which allows 65 per cent of the available daylight in while keeping 49 per cent of the heat out.

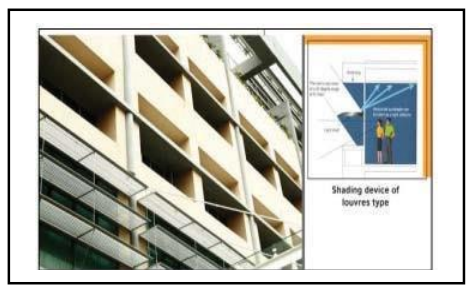

Picture 1.4: Punch Hole Windows Source: KETTHA building

\subsection{Active Element}

\subsubsection{Air Conditioning}

Air conditioning in the KETTHA building has been made efficient in three ways. First, the air conditioning is not controlled from one central point. Instead, it can be switched off in individual rooms or areas while remaining on in others, depending on whether these areas are occupied or not. Each floor of the building has its own air handling unit (AHU) which is subdivided into smaller zones, and the volume of chilled air channeled into each zone is controlled by factors such as temperature and occupancy. Second, the air conditioning is set to keep occupied areas in the building at 25C as opposed to anything lower, which not only sometimes becomes uncomfortable for occupants, but also uses unnecessary energy. Computer modeling shows that if the room temperature is $20 \mathrm{C}$ rather than $24 \mathrm{C}$, total electricity consumption of the building increases by one third due to the higher cooling load. Third, Putrajaya as a whole receives chilled water from a district cooling plant which operates on natural gas and which pumps cold water through underground pipes to all the buildings in the area. This chilled water is used for air conditioning purposes, reducing the need for individual electric air conditioning chillers in the different ministerial and commercial 
buildings.

\subsubsection{Innovative Lighting System}

In addition to the windows and atrium, which reduce the need for artificial lighting in the building, energy use in the KETTHA building is optimized by high-efficiency light fixtures with electronic ballasts instead of the normal energy consuming magnetic ballasts. The lights function automatically to switch off when there is sufficient daylight to provide an illumination level of about 350 lumen (lux), meeting the new standard for non-residential buildings as stated in the MS 1525 of between 300-400 lux, which has been reduced from an overly bright 500 lux previously. In addition, the lighting system is combined with a motion detector which automatically switches off the lights and air conditioning in a room once no physical motion is detected, indicating that the room is vacant. The lighting system has distinct circuits such that lights along the windows operate independently of the others. Given these measures, electricity consumption for lighting and cooling in the KETTHA building has been reduced by $50 \mathrm{kWh} / \mathrm{m} 2$ per year.

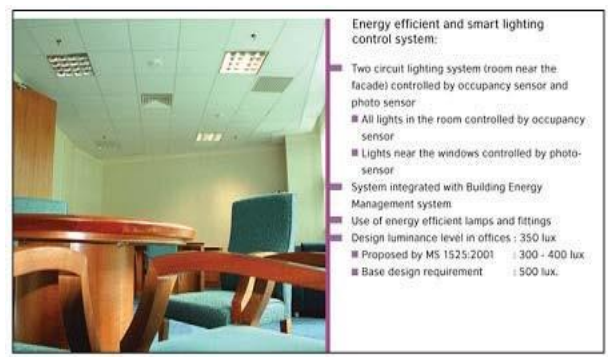

Picture 1.5: Lighting Control System

Source: KETTHA building

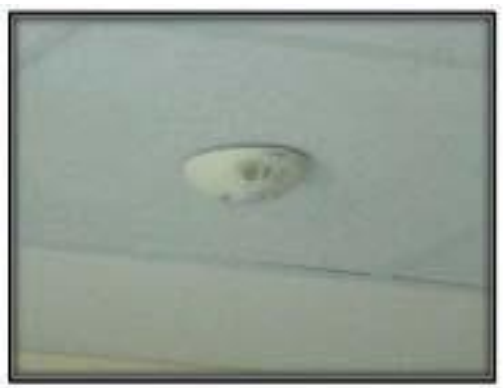

Picture 1.6: Occupancy Sensor

Source: KETTHA building 


\subsubsection{Energy Efficient Office Appliances}

Office equipment such as computers, printers and copy machines, are responsible for an increasing of electricity consumption, and thereby also responsible for additional increase in cooling load. Therefore, special emphasis has been made in the KETTHA Building to reduce the electricity consumption for equipment, and a guideline for procurement of energy efficient office equipment has been produced. Simulation with the Energy-10 computer tool confirms the significance of office equipment on the overall energy consumption.

Using energy efficient office equipment, the electricity consumption for the equipment can be reduced from 25 to only $10 \mathrm{kWh}$ per $\mathrm{m} 2$ per year. In addition to this, the cooling load is reduced by further $10 \mathrm{kWh}$ per $\mathrm{m} 2$ per year. The main energy consuming office equipment in modern office is the Personal Computer, with its screen. Energy consumption is reduced by purchase of energy labeled computers with software thatautomatically reduced energy consumption during idle periods. Furthermore, flat screens are much more energy efficient than the traditional bulky CRT screen. Also, flat screens provide better user comfort with less reflection than the CRT screens, and they take up much less space on the desk. Therefore, all in all, the extra cost of flat screen, now typically less than RM 1,000 can easily be defended from an overall perspective. Portable lab top computers are much more energy efficient than stationary computers because they are optimized for maximum battery life. The extra price for a lab top compared to a desktop computer with flat screen is now lesser than RM 1,000. This extra investment will often be very attractive given the extra flexibility and given that the energy consumption per PC reduces to $\sim 80 \mathrm{~W}$ (with flat screen) and to $30 \mathrm{~W}$ for the laptop. For comparison, energy consumption for stationary computer with CRT screen is $\sim 150 \mathrm{~W}$.

\subsubsection{Comprehensive Energy Management System}

A comprehensive energy management system (EMS) is a prerequisite for actually achieving the low energy consumption, for which the building has been design. The energy management system monitors on a continuous basis the energy consumption of the building. This allows for the comparison of actual energy consumption with predicted consumption and with typical previous consumption, and action can be taken if abnormal high energy consumption registered.

\subsubsection{PV System}

Other additional element in this KETTHA building are the installed solar photovoltaic system capacity is $3.3 \mathrm{kWp}$ (kilowatt peak). This solar covered energy through the Water wall powered by a small grid- connected photo-voltaic system-3kWp PV system and is used to run the Air Conditioning Motor pump. 60 units of PV system-solar Photovoltaic are located on the roof top of the building the system consists of the following major components:

\section{Solar Array - 60 units of GTF 55W CdTe}

2. Thin Film solar modules ( 6 in series by 10 parallel in order to achieve nominal system voltage of $378 \mathrm{Vdc}$. 
3. Support structures made of hot-dipped galvanized steel

4. Field and array junction box

5. Grid connected locally to building system through a $3.0 \mathrm{~kW}$ inverter

6. Protection devices and cabling Digital AC kilowatt-hour meter to monitor the energy generated by the solar photovoltaic

7. Two nos. of centrifugal pumps type Grundfos model $\mathrm{CH} 18-15$

The PV panels generate Direct Current (DC) which in turn is converted into Alternate Current (AC) through the inverter. The inverter operates in parallel with grid supply. Any excess solar energy will be diverted to local loads in the building.

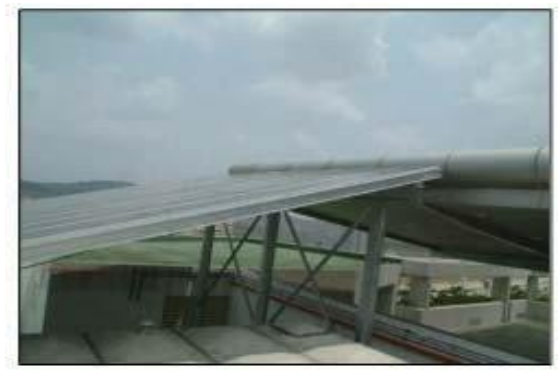

Picture 1.8: Solar Photovoltaic System at the Roof

Source: KETTHA building

\subsubsection{Rainwater Harvest System}

This demonstrates rain water harvest system from the secondary roof. The water collected are used for irrigation purposes and this will help to reduce water consumption.

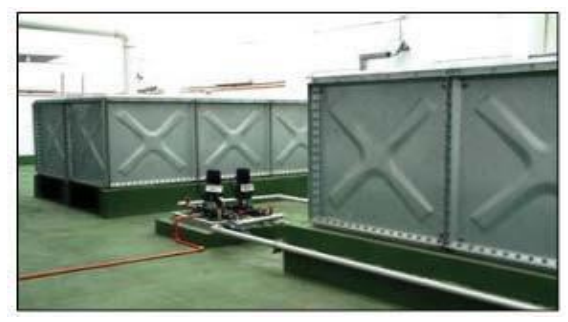

Picture 1.9: Rain Water Harvest Water Tank Source: KETTHA building

\subsection{Findings and Conclusion}

The findings revealed that users have mixed feeling towards light and space especially with the use of new working practices i.e. hot desking, hotelling etc. And these also influence by 
Zainordin, E., et.al, / Asian Journal of Environment-Behaviour Studies (ajE-Bs), 3(6) Jan / Feb 2018 (p. 201-211)

the nature of their jobs as well as their position in the office. Nonetherless, energy efficient building does provide thermal comfort, healthy living, lower heating costs and an overall high degree of user satisfaction. Table 1 below summarised the criteria and average index, Figure 1 illustrates the findings.

Table 1: Criteria and Average Index

\begin{tabular}{|l|c|c|}
\hline & Criteria & Average Index \\
\hline 1 & Electrical lighting & 3.8 \\
\hline 2 & Natural lighting & 4.02 \\
\hline 3 & Work place planning & 4 \\
\hline 4 & General space planning & 4.02 \\
\hline 5 & Office equipment & 4.09 \\
\hline 6 & Working condition & 4.41 \\
\hline 7 & Ventilation & 4.05 \\
\hline 8 & Air freshness & 3.92 \\
\hline 9 & Air conditioning & 3.75 \\
\hline
\end{tabular}

\section{Average Index}

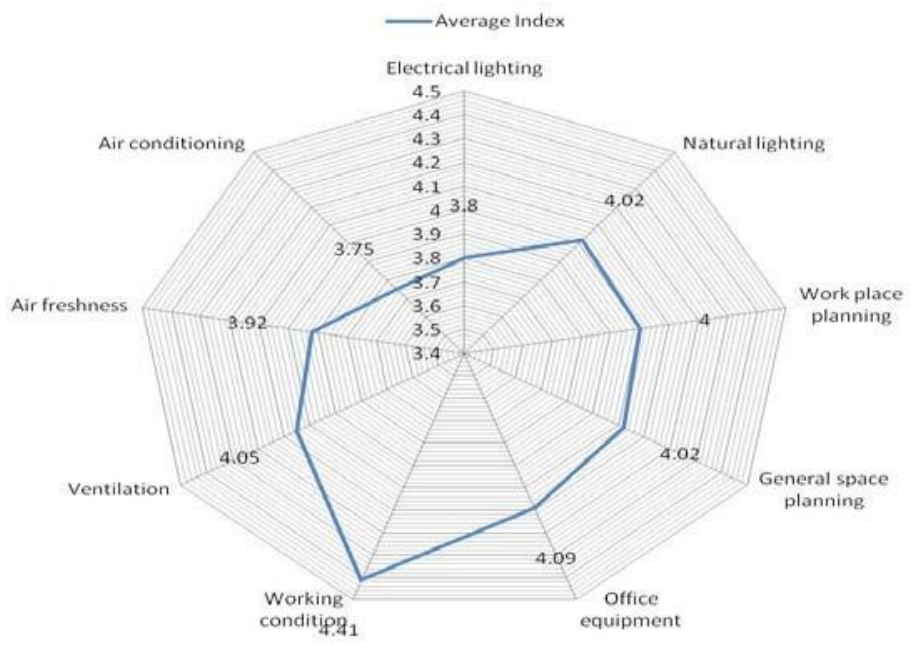

Figure 1: RadarDiagram oftheUsers'PerceptionTowards the Criteria of Energy EfficientBuilding 


\section{References}

Å. L. Hauge, J. Thomsen \& T. Berker (2010), User Evaluations of Energy Efficient Buildings-Literature Reviewand FurtherResearch, proceedingfromRenewal Energy Conference, Norway

Chia Chin Wah (2010) The efficiency of zero-energy approach in $21^{\text {st }}$ century building construction, Master dissertation, heriott Watt, unpublished

Development and Land Use Policy Manual (2000) Energy Efficient Building Design. [Online]. [Available: http://www.fremantle.wa.gov.au/council/ resource/DBH12_Energy_Efficient.pdf accessed $2^{\text {nd }}$ January 2010].

United Nations. (1991) Energy Efficient Design: A Guide to Energy Efficiency and Solar Applications in Building Design. ECE Energy Series No. 9. New York: United Nations.

Janssen, R. (2004) Towards Energy Efficient Buildings in Europe. London: The European Alliance of Companies for Energy Efficiency in Buildings.

Ministry of Finance Malaysia, Ninth Malaysia Plan 2006-2010 www.kettha.gov.my 